\title{
Variabilidad en el contenido de polifenoles, actividad biológica y antihelmíntica de extractos metanol:agua de las hojas de Gymnopodium floribundum Rolfe
}

Guadalupe Isabel Ortíz-Ocampo ${ }^{\text {a }}$

Carlos Alfredo Sandoval-Castro ${ }^{\text {a }}$

Gabriela Mancilla-Montelongo ${ }^{\mathrm{b}}$

Gloria Sarahi Castañeda-Ramírez ${ }^{\text {a }}$

José Israel Chan Pérez ${ }^{a}$

Concepción Capetillo Leal ${ }^{\text {a }}$

Juan Felipe de Jesús Torres-Acosta ${ }^{a *}$

${ }^{\text {a }}$ Universidad Autónoma de Yucatán, Facultad de Medicina Veterinaria y Zootecnia. Km 15.5 Carretera Mérida-Xmatkuil, 97315, Mérida, Yucatán, México.

b CONACYT-Universidad Autónoma de Yucatán, Facultad de Medicina Veterinaria y Zootecnia. Km 15.5 Carretera Mérida-Xmatkuil, 97315, Mérida,Yucatán, México.

*Autor de correspondencia: tacosta@correo.uady.mx

\section{Resumen:}

Se determinó el efecto del mes de cosecha y edad de las hojas de Gymnopodium floribundum sobre el contenido de compuestos polifenólicos (fenoles totales (FT), taninos totales (TT) y taninos condensados (TC)) de extractos metanol:agua. Además, se determinó la actividad biológica de los polifenoles medida como la capacidad de precipitar proteína (PP), inhibir la eclosión de huevos (EH), y el desenvaine larval (IDL) de Haemonchus contortus. Se cosecharon hojas de G. floribundum en cuatro meses del año: diciembre, marzo, junio y 
septiembre. Se obtuvieron 24 extractos metanol:agua (70:30), 12 producidos de hojas de edad variada (EV) y 12 de hojas de 90 días (E90). Todos los extractos ocasionaron similar PP independientemente de edad y mes de cosecha. La inhibición de la EH solo fue significativa para el extracto EV de diciembre $\left(\mathrm{CE}_{50}=374.4 \mu \mathrm{g} / \mathrm{ml} ; P<0.05\right)$. Los extractos de hojas E90 mostraron una $\mathrm{CE}_{50}>1500 \mu \mathrm{g} / \mathrm{ml}$ en diciembre, junio y septiembre. Aunque todos los extractos inhibieron el desenvaine larval (IDL), la menor $\mathrm{CE}_{50}$ fue la del extracto de hojas $\mathrm{EV}$ de junio $\left(\mathrm{CE}_{50}=80.4 \mu \mathrm{g} / \mathrm{ml} ; \quad P<0.05\right)$. La incubación de extractos con polivinilpolipirrolidona (PVPP) limitó la IDL $(P<0.05)$, pero los polifenoles solo explicaron parte de esa actividad. En conclusión, el contenido de TC de los extractos de hojas de $G$. floribundum depende de su edad y mes de cosecha. Los polifenoles mostraron actividad de PP y se asociaron parcialmente con la IDL. Sin embargo, los polifenoles no explican la actividad contra huevos de $H$. contortus.

Palabras clave: Polifenol, Antihelmíntico, Haemonchus contortus, Precipitación de proteína, Extractos, Taninos.

Recibido: 08/12/2020

Aceptado: 10/05/2021

\section{Introducción}

Los ovinos y caprinos que ramonean en la selva baja caducifolia (SBC) de Yucatán consumen cantidades variables de follaje de una amplia variedad de especies de plantas ricas en $\operatorname{taninos}^{(1)}$. Una de las especies más consumidas es el Gymnopodium floribundum que es un árbol de talla baja abundante en la SBC y que ha sido estudiado por su contenido de compuestos secundarios (CS) ${ }^{(2)}$. Entre los CS reportados para G. floribundum se encuentran los compuestos volátiles (E)-ocimeno, 2-etil-1-hexanol y linalool presentes en sus flores ${ }^{(3)}$. Las hojas de esta especie contienen otros CS importantes como los polifenoles, i.e. fenoles totales (FT), taninos totales (TT) y taninos condensados $(\mathrm{TC})^{(1,2)}$. Los polifenoles pudieran estar involucrados en la defensa de las plantas contra infecciones por bacterias y hongos fitopatógenos y también limitan el consumo de las hojas por los herbívoros vertebrados e invertebrados $^{(4,5,6)}$. Esto último pudiera estar relacionado con las propiedades astringentes de los polifenoles. La capacidad de los polifenoles para limitar el consumo de hojas por parte de los herbívoros también ha sido descrita para los pequeños rumiantes pastoreando en algunos ecosistemas, ocasionando baja productividad animal ${ }^{(7)}$. Sin embargo, el efecto de reducir el consumo no se ha encontrado en los pequeños rumiantes ramoneando en la $\mathrm{SBC}^{(8)}$. Por el contrario, ovinos y caprinos ramoneando en la SBC buscan consumir el follaje de diferentes especies de plantas con elevado contenido de TC posiblemente como una 
estrategia para bloquear el exceso de nitrógeno en su dieta, favoreciendo un mejor balance de nitrógeno y energía, y reduciendo la necesidad de eliminar nitrógeno en la orina ${ }^{(2)}$. Esto se debe a que los polifenoles tienen la capacidad de precipitar proteínas (PP) en la dieta ${ }^{(9,10)}$. La PP es la propiedad de los polifenoles para formar complejos con proteínas y otras macromoléculas que poseen grupos carbonilo y amino, formando enlaces de hidrógeno con macromoléculas susceptibles de autooxidación para formar enlaces covalentes ${ }^{(5)}$. Se desconoce si la actividad de PP de los polifenoles varía a lo largo del año en las hojas de $G$. floribundum.

Por otro lado, estudios recientes han demostrado que los extractos del follaje de $G$. floribundum tienen actividad antihelmíntica (AH) in vitro contra huevos y larvas de $H$. contortus $^{(11,12)}$, y se ha demostrado que los polifenoles están involucrados en dicha actividad $^{(12) .}$ La actividad $\mathrm{AH}$ in vitro fue confirmada recientemente en estudios in vivo usando follaje de G. floribundum en la dieta de corderos infectados con H. contortus $^{(13)}$. Lo anterior permite considerar a las hojas de G. floribundum como un alimento con potencial nutracéutico que pudiera ser usado en el control de nematodos gastrointestinales (NGI). Sin embargo, se ha reportado variabilidad en el contenido de polifenoles en las hojas de los árboles forrajeros ricos en polifenoles de la SBC como Acacia pennatula, Lysiloma latisiliquum y Psicidia piscipula ${ }^{(14)}$. Así mismo, las hojas de G. floribundum muestran variación en su contenido de polifenoles, siendo mayor en época de lluvias (33.8\%), periodo de rápido crecimiento foliar, y menor en época de secas $(9.5 \%)$, cuando los árboles pierden su follaje ${ }^{(2,13)}$. Recientemente, un estudio anual de las hojas de G. floribundum confirmó que la edad de las hojas y el mes de cosecha afectan su composición bromatológica y su contenido de polifenoles ${ }^{(15)}$. Lo anterior sugiere que es indispensable estudiar la variabilidad del contenido de compuestos bioactivos en las plantas para hacer uso racional de estos recursos como nutracéuticos ${ }^{(6,16,17)}$.

Hasta el momento no existen estudios que identifiquen la variabilidad en el contenido de polifenoles y su actividad biológica en árboles tropicales. Este estudio determinó el efecto del mes de cosecha y edad de las hojas de G. floribundum sobre el contenido de compuestos polifenólicos de extractos metanol:agua y la actividad biológica de los polifenoles medida como su capacidad de precipitar proteína (PP), inhibir la eclosión de huevos e inhibir el desenvaine larval de $H$. contortus.

\section{Material y métodos}

\section{Lugar de colecta de material de Gymnopodium floribundum}

El estudio se llevó acabo en el periodo comprendido entre el 18 de diciembre de 2017 y el 21 de diciembre de 2018. Se realizó en un área experimental de SBC de 12,000 m² $(50 \times 240$ 
m) ubicado en la Facultad de Medicina Veterinaria y Zootecnia de la Universidad Autónoma de Yucatán, México (2051'93.2" N y 89³7'11" O, a 10 msnm). El área experimental cuenta con un clima $\mathrm{AW}_{0}$ (cálido subhúmedo con lluvias en verano). El tipo de suelo se clasifica como cambisol y luvisol. La temperatura máxima promedio fue $32{ }^{\circ} \mathrm{C}$ y la mínima de $16{ }^{\circ} \mathrm{C}$ con una precipitación pluvial anual que varía de $984.4 \mathrm{~mm}$ a $1,092 \mathrm{~mm}$, distribuida de junio a noviembre ${ }^{(18)}$.

\section{Colecta y producción de extractos de hojas de Gymnopodium floribundum}

El material vegetativo se cosechó trimestralmente a mano en las siguientes fechas: (a) 18 al 21 de diciembre de 2017 y 2018, (b) 18 al 21 de marzo 2018, (c) 18 al 21 de junio 2018, y (d) 18 al 21 de septiembre de 2018. Se conformaron tres muestras compuestas en los diferentes meses de cosecha. Cada muestra se formó con la totalidad de las hojas de cuatro árboles. Las muestras de hojas de edad variada (EV) incluyeron las hojas de ejemplares no defoliados previamente. Las muestras de hojas de 90 días de edad (E90) se obtuvieron de los mismos ejemplares a los 90 días postcosecha. A las hojas frescas de cada muestra se les añadió metanol:agua (70:30 v/v) y se homogenizaron con una licuadora (Oster®, México) durante $<1$ min, hasta lograr un tamaño de partícula homogéneo. A la mezcla se le adicionó ácido ascórbico y se dejó macerar por 24 h. Posteriormente, la mezcla se filtró usando gasa y papel filtro de poro grande No. 50 (Tequimec SDRL, México). Para obtener el extracto, el disolvente (metanol) se evaporó a $50{ }^{\circ} \mathrm{C}$ empleando presión reducida (rotavapor Ika ${ }^{\circledR}$, Alemania). La clorofila y los lípidos se removieron de la fracción acuosa utilizando cloruro de metileno (1:1 v/v, 3-7 lavados). Finalmente, el resto de la fracción se liofilizó, se envasó y se mantuvo en refrigeración a $4{ }^{\circ} \mathrm{C}$ hasta su uso.

\section{Determinación de polifenoles en los extractos}

Se cuantificó la cantidad de fenoles totales (FT), taninos totales (TT) y taninos condensados (TC) de cada extracto obtenido de cada edad y mes de cosecha. La técnica de Folin-Ciocalteu se usó para determinar los $\mathrm{FT}^{(19)}$. El contenido de TT se determinó mediante la técnica de Folin-Ciocalteu + PVPP $^{(19)}$. El contenido de TC de los extractos se determinó mediante la prueba de vainillina ${ }^{(20)}$.

\section{Producción de huevos y larvas de Haemonchus contortus}

Los huevos y larvas en fase infectiva $\left(\mathrm{L}_{3}\right)$ de $H$. contortus se obtuvieron de animales donadores infectados artificialmente con $H$. contortus (aislado Paraíso, Yucatán, México). Se colectaron huevos frescos de las heces de cada animal donante. Las heces de los donantes se colectaron directamente del recto de los mismos, usando bolsas de plástico nuevas y las heces se procesaron en las $3 \mathrm{~h}$ siguientes a su recolección. Aproximadamente $10 \mathrm{~g}$ de heces 
fueron macerados en $100 \mathrm{ml}$ de agua purificada. La suspensión se filtró con una gasa. El material filtrado se centrifugó $\left(168 \mathrm{xg} / 5 \mathrm{~min} / 21{ }^{\circ} \mathrm{C}\right)$ usando tubos cónicos de $15 \mathrm{ml}$. El sobrenadante se desechó y el sedimento se mezcló con una solución saturada elaborada con azúcar de caña comercial (densidad relativa 1.28). Una vez mezclado, el sedimento se homogeneizó mediante un vortex. La suspensión se centrifugó (168 x $\left.g / 5 \mathrm{~min} / 21^{\circ} \mathrm{C}\right)$. La capa superficial de la solución se recuperó con un asa bacteriológica. Los huevos se lavaron tres veces con agua purificada para eliminar el azúcar restante y se volvieron a suspender en tubos de $15 \mathrm{ml}$ que contenían $10 \mathrm{ml}$ de solución salina de fosfatos (PBS $0.01 \mathrm{M}$ : $\mathrm{NaCl} 0.138 \mathrm{M}, \mathrm{KCl}$ $0.0027 \mathrm{M}, \mathrm{KH}_{2} \mathrm{PO}_{4}$ 0.001M, $\mathrm{Na}_{2} \mathrm{HPO}_{4}$ 0.0081M; pH 7.4; Sigma® USA). Se determinó la concentración de huevos y la suspensión se diluyó a 150 huevos / $\mathrm{ml}$ de PBS para su uso en la prueba de eclosión de huevos $(\mathrm{EH})^{(12)}$.

Para la prueba de inhibición del desenvaine larval (IDL) se recuperaron heces de los animales donadores y se enjuagaron en un colador con agua corriente para eliminar la hierba u otros desechos. Las heces se colocaron en placas Petri (15 cm de diámetro), se incubaron por cinco días a $28^{\circ} \mathrm{C}$ y se hidrataron a diario manualmente con un rociador de agua. Las larvas $\mathrm{L}_{3} \mathrm{se}$ cosecharon usando la técnica de Baermann y se almacenaron a $4{ }^{\circ} \mathrm{C}$ hasta su uso. La edad de las larvas empleadas en la IDL fue de entre 2 y 5 semanas $^{(12,21)}$.

\section{Actividad antihelmíntica in vitro contra huevos de Haemonchus contortus}

Se prepararon soluciones madre $(10,000 \mu \mathrm{g} / \mathrm{ml}$ de PBS) para cada extracto probado. Se usó PBS como control negativo. Se prepararon alícuotas de $0.5 \mathrm{ml}$ de las distintas diluciones (3600, 2400, 1200, 600, 300 y $150 \mu \mathrm{g} / \mathrm{ml}$ de PBS) a partir de la solución madre de cada extracto de planta en placas de 24 pozos. Se adicionaron $0.5 \mathrm{ml}$ de la suspensión de huevos (150 huevos / ml) a cada pozo hasta lograr un volumen final de $1 \mathrm{ml}$. Se utilizaron seis réplicas para cada concentración de extracto. Las placas de pozos múltiples se incubaron a $28{ }^{\circ} \mathrm{C}$ (48 h). Al final de dicho proceso, se agregaron dos gotas de Lugol a cada pozo para detener la eclosión, además de teñir los huevos y las larvas ${ }^{(22,23)}$.

Se contaron los huevos no larvados, los huevos larvados y las larvas $\mathrm{L}_{1}$ de cada pozo y se calculó el porcentaje de eclosión con la fórmula:

Eclosión huevos\%= (100) (larvas $\left.\mathrm{L}_{1}\right) /\left(\right.$ huevos larvados + huevos + larvas $\left.\mathrm{L}_{1}\right)$

Para determinar el papel de los polifenoles en el efecto AH de los extractos, se utilizó un inhibidor de los taninos, la polivinilpolipirrolidona (PVPP) ${ }^{(11,19)}$. En estos bioensayos se incluyó únicamente la concentración de 3,600 $\mu \mathrm{g}$ de extracto / ml PBS (con y sin PVPP) y sus respectivos controles $\mathrm{PBS}^{(24)}$. 


\section{Prueba de inhibición del desenvaine larval (IDL) de Haemonchus contortus}

Se agregaron 1,000 $\mu \mathrm{l}$ de suspensión de $\mathrm{L}_{3}(\sim 1,000 / \mathrm{ml})$ a cada tubo para obtener las concentraciones finales de extracto $(1,200,600,400,200,100,30 \mu \mathrm{g} / \mathrm{ml})$ a partir de las respectivas soluciones madre de G. floribundum. Como control negativo se usó un tubo que contenía 1,000 $\mu \mathrm{l}$ de PBS sin extracto. Las larvas se incubaron durante $3 \mathrm{~h}\left(24{ }^{\circ} \mathrm{C}\right)$. Se colocaron alícuotas de cada suspensión de larvas en microviales (200 $\mu \mathrm{l}$ en cada uno.) con cuatro repeticiones para cada concentración y el control PBS. El desenvaine de $\mathrm{L}_{3}$ fue inducido artificialmente con una solución de hipoclorito (2.2\%) e hidróxido de sodio $(0.7 \%)$ (Clorox $\left.{ }^{\circledR}\right)$ diluido a 1/300,1/343, 1/400 y 1/480. La cinética del desenvaine se estimó contando larvas con vaina y sin vaina con un microscopio (10x), y se registró el desenvaine a los $0,20,40$ y $60 \min ^{(23)}$. Se calculó el porcentaje de desenvaine de larvas $\mathrm{L}_{3}$ para cada punto de medición usando la siguiente fórmula:

Desenvaine $(\%)=(100)\left(\right.$ total de $\mathrm{L}_{3}$ sin vaina $) /\left(\mathrm{L}_{3}\right.$ con vaina $+\mathrm{L}_{3}$ sin vaina $)$

Para determinar el papel de los polifenoles en el efecto AH de los extractos, se utilizó un inhibidor de taninos, el PVPP ${ }^{(12,19)}$. Para cada extracto se incluyó únicamente la dosis de 1200 $\mu \mathrm{g} / \mathrm{ml}$ PBS (con y sin PVPP) y sus respectivos controles PBS.

\section{Precipitación de proteína mediante la técnica de difusión radial}

Se determinó la PP como un indicador de la actividad biológica de los polifenoles. Se realizó mediante el ensayo de difusión radial ${ }^{(25)}$. La técnica identifica la capacidad de los polifenoles para unirse a moléculas de proteína (por ejemplo la hemoglobina bovina) en una placa con agar. Se preparó gel de agarosa al 1\% (Baker®, Alemania) en tampón de acetato y hemoglobina bovina (Sigma ${ }^{\circledR}$, Alemania) (100 mg/L agar). El pH se ajustó a 5.0 con $\mathrm{NaOH}$. Se colocaron $10 \mathrm{ml}$ de agar en placas de Petri de $10 \mathrm{~cm}$ de diámetro. En el agar de cada placa de Petri se formaron cinco pozos de $4 \mathrm{~mm}$ de diámetro cada uno (uno en el centro y las cuatro restantes en las posiciones de 0, 90, 180 y 270 grados). En estos últimos se adicionaron 15 $\mu \mathrm{l}$ de una solución de cada extracto y se incubaron durante $48 \mathrm{~h} \mathrm{a} 25^{\circ} \mathrm{C}$. Al término de ese tiempo se midió el halo que se formó alrededor de cada pozo. Este halo es el resultado de la precipitación de la hemoglobina por acción de los polifenoles de cada extracto. La PP se ponderó por la concentración de TT, FT y TC contenida en cada extracto evaluado. Para esto se utilizó la fórmula descrita por Hagerman ${ }^{(25)}$ :

$\mathrm{PP}=\left(\left(\mathrm{D} 2^{2}-\mathrm{D} 1^{2}\right) / \mathrm{T}\right)$; donde: $\mathrm{D} 1$ : diámetro menor poceta $(\mathrm{mm})$; D2: diámetro mayor $(\mathrm{mm})$; T: Fenoles totales o taninos totales o taninos condensados (mg). 


\section{Procesamiento de datos y análisis estadísticos}

Se determinó el efecto de la edad de las hojas (EV o E90) y el mes de cosecha, así como su interacción sobre la composición de polifenoles (FT, TT, TC) mediante respectivos modelos lineales generalizados (MLG). Posteriormente la comparación de medias se realizó mediante la prueba de Tukey con $\alpha<0.05^{(26)}$.

Para la prueba de la EH, se registró el número de huevos que permanecieron en estado de mórula (MOE), huevos que desarrollaron una larva, pero no eclosionaron (LFE) y número de larvas que emergieron de los huevos como resultado de su exposición a diferentes extractos en la concentración respectiva previamente descrita. Esta información se utilizó para determinar la tasa de eclosión de huevos (\%EH) y la inhibición de la eclosión de huevos (\% IEH) de la siguiente manera ${ }^{(24,27)}$ :

$$
\begin{gathered}
\% \mathrm{EH}=\frac{\text { Número de larvas }}{\text { número de huevos morulados }+ \text { huevos con larva }+ \text { número de larvas }} \times 100 \\
\% \mathrm{IEH}=100-\% \mathrm{EH}
\end{gathered}
$$

El porcentaje de huevos morulados que no formaron larva (efecto ovicida) se calculó así:

$$
\% \mathrm{MOE}=\frac{\text { Número de huevos morulados }}{\text { número de huevos morulados }+ \text { huevos con larva }+ \text { número de larvas }} \times 100
$$

El porcentaje de huevos con larva que no eclosionó (\%LFE) se calculó así:

$$
\% \text { LFE }=\frac{\text { Número de huevos que contienen larvas }}{\text { número de huevos morulados }+ \text { huevos con larva }+ \text { número de larvas }} \times 100
$$

El porcentaje del desenvaine (\%D) y el de inhibición del desenvaine (\%IDL) se determinaron con las siguientes fórmulas ${ }^{(28)}$ :

$$
\begin{gathered}
\% \mathrm{D}=\frac{\text { Larvas } \mathrm{L}_{3} \text { con vaina }}{\text { larvas con vaina }+ \text { larvas sin vaina }} \times 100 \\
\% \mathrm{IDL}=100-\% \mathrm{D}
\end{gathered}
$$

La inhibición de la EH y los resultados de IDL obtenidos para los diferentes extractos se analizaron con los respectivos modelos lineares generalizados (MLG) para evaluar las diferencias entre el control PBS y las diferentes concentraciones de extracto analizados. Los datos obtenidos de las incubaciones de PVPP de cada extracto se analizaron usando un diseño completamente al azar (MLG con comparaciones realizadas con el grupo control respectivo para cada extracto) ${ }^{(26)}$. 
La concentración efectiva requerida para inhibir el $50 \%$ de la eclosión de huevos, o el $50 \%$ del desenvaine de las $\mathrm{L}_{3}$ (concentración efectiva $50 \%$; $\mathrm{CE}_{50}$ ) se estimó con los datos obtenidos de las pruebas de EH e IDL respectivamente para cada extracto de planta probado usando el software PoloPlus 1.0 $0^{(29)}$.

Se realizó la prueba de Shapiro-Wilk para evaluar la normalidad de los datos de PP, EH e IDL. Se analizó la actividad biológica respectiva (PP, EH e IDL) mediante un MLG y los efectos principales de la edad de las hojas (EV y E90) y el mes de cosecha (cuatro meses de cosecha), así como su interacción. La comparación de medias se realizó mediante la prueba de Tukey con $\alpha<0.05$. Adicionalmente se realizaron respectivas correlaciones de Pearson para determinar la asociación entre el contenido de polifenoles (FT, TT y CT), y la PP, así como de las $\mathrm{CE}_{50}$ de $\mathrm{EH}$ e IDL respectivamente ${ }^{(26)}$.

\section{Resultados}

En el Cuadro 1 se muestra el contenido de FT, TT y TC, en los extractos de las muestras compuestas de hojas de G. floribundum de diferentes edades. El contenido de FT y TT no fue modificado por el mes de cosecha, la edad o la interacción $(P>0.05)$. Sin embargo, sí se encontraron diferencias significativas en el contenido de TC debidas a la interacción entre la edad de las hojas y el mes de cosecha, como se puede apreciar para los extractos de marzo (secas) y de junio (lluvias) de las hojas EV ( $P<0.05)$. Así mismo, en el mes de junio (lluvia) se observó un mayor contenido de TC en las hojas EV que en las hojas E90 $(P<0.05)$.

Cuadro 1: Efecto de la edad de las hojas y del mes de cosecha sobre el contenido de polifenoles en los extractos metanol:agua de hojas de Gymnopodium floribundum

\begin{tabular}{|c|c|c|c|}
\hline & $\begin{array}{l}\text { Fenoles } \\
\text { Totales }(\%)\end{array}$ & $\begin{array}{l}\text { Taninos } \\
\text { totales }(\%)\end{array}$ & $\begin{array}{l}\text { Taninos } \\
\text { condensados }(\%) *\end{array}$ \\
\hline \multicolumn{4}{|c|}{ Extractos de hojas de edad variable (EV) } \\
\hline Diciembre & $19.3^{\mathrm{a}}$ & $2.9^{\mathrm{a}}$ & $65.9^{\mathrm{ab}}$ \\
\hline Marzo & $20.2^{\mathrm{a}}$ & $4.4^{\mathrm{a}}$ & $48.7^{\mathrm{b}}$ \\
\hline Junio & $28.2^{\mathrm{a}}$ & $6.7^{\mathrm{a}}$ & $131.7^{\mathrm{a}}$ \\
\hline Septiembre & $26.1^{\mathrm{a}}$ & $10.4^{\mathrm{a}}$ & $106.9^{\mathrm{ab}}$ \\
\hline \multicolumn{4}{|c|}{ Extractos de hojas de edad de 90 días (E90) } \\
\hline Diciembre & $20.0^{\mathrm{a}}$ & $5.4^{\mathrm{a}}$ & $69.5^{\mathrm{ab}}$ \\
\hline Marzo & $20.8^{\mathrm{a}}$ & $9.0^{\mathrm{a}}$ & $65.9^{\mathrm{ab}}$ \\
\hline Junio & $24.5^{\mathrm{a}}$ & $6.4^{\mathrm{a}}$ & $49.8^{\mathrm{b}}$ \\
\hline Septiembre & $27.6^{\mathrm{a}}$ & $12.9^{\mathrm{a}}$ & $99.2^{\mathrm{ab}}$ \\
\hline Error Estándar & 1.83 & 2.80 & 13.50 \\
\hline
\end{tabular}




\section{Prueba de eclosión de huevos (EH)}

El extracto de hojas EV cosechadas en diciembre fue el único que mostró actividad sobre la $\mathrm{EH}$ de $H$. contortus $\left(\mathrm{CE}_{50}=374.4 \mu \mathrm{g} / \mathrm{ml}\right)$. En el Cuadro 2 se puede observar que los extractos de hojas E90 de G. floribundum de diciembre, junio y septiembre mostraron una baja actividad sobre la $\mathrm{EH}\left(\mathrm{CE}_{50}>1,500 \mu \mathrm{g} / \mathrm{ml}\right)$, mientras que para el extracto de marzo no fue posible calcular la $\mathrm{CE}_{50}$.

Cuadro 2: Efecto de la edad de las hojas y del mes de cosecha sobre la concentración efectiva ( $\left.\mathrm{CE}_{50}\right)$ e intervalo de confianza de los extractos metanol: agua de hojas de Gymnopodium floribundum sobre la eclosión de huevos de Haemonchus contortus

\begin{tabular}{|c|c|c|}
\hline & $\begin{array}{l}\text { CE50 } \\
(\mu \mathrm{g} / \mathrm{ml})\end{array}$ & $\begin{array}{l}\text { IC95\% } \\
(\mu \mathrm{g} / \mathrm{ml})\end{array}$ \\
\hline \multicolumn{3}{|c|}{ Extractos de hojas de edad variable (EV) } \\
\hline Diciembre & $374.4^{\mathrm{a}}$ & $282.08-473.66$ \\
\hline Marzo & Sin actividad & - \\
\hline Junio & Sin actividad & - \\
\hline Septiembre & Sin actividad & - \\
\hline \multicolumn{3}{|c|}{ Extractos de hojas de 90 días de edad (E90) } \\
\hline Diciembre & $3088.3^{\mathrm{b}}$ & $2262.45-4192.55$ \\
\hline Marzo & Sin actividad & - \\
\hline Junio & $1907.5^{\mathrm{b}}$ & $1783.75-2029.55$ \\
\hline Septiembre & $1575.0^{\mathrm{b}}$ & $981.26-2395.96$ \\
\hline
\end{tabular}

En el Cuadro 3 se aprecia el efecto de bloquear los polifenoles mediante PVPP sobre la proporción de MOE, LFE y $\mathrm{L}_{1}$ de huevos incubados con los diferentes extractos de $G$. floribundum. Los diferentes extractos mostraron una actividad más orientada a retener a las larvas $\mathrm{L}_{1}$ dentro de los huevos (LFE). Sin embargo, al bloquear a los polifenoles se observó mayor actividad ovicida para los extractos de hojas EV (diciembre y marzo). Los análisis de correlación no mostraron asociación entre el contenido de FT, TT o TC, y la $\mathrm{CE}_{50}$ de inhibición de la eclosión de huevos $(P>0.05)$. 
Cuadro 3: Efecto de la incubación de huevos de Haemonchus contortus en diferentes extractos de Gymnopodium floribundum a la concentración de 3,600 $\mu \mathrm{g} / \mathrm{ml}$, con y sin polivinilpolipirrolidona (PVPP), sobre la proporción (\%) de huevos que permanecieron en estado de mórula (MOE), larvas sin eclosionar de sus huevos (LFE) y larvas $\left(\mathrm{L}_{1}\right)$

\begin{tabular}{|c|c|c|c|c|c|}
\hline & $\begin{array}{l}\text { Etapa de } \\
\text { vida }\end{array}$ & $\begin{array}{l}\text { PBS } \\
(\%)\end{array}$ & $\begin{array}{l}3,600 \mu \mathrm{g} / \mathrm{ml} \\
(\%)\end{array}$ & $\begin{array}{l}3,600 \mu \mathrm{g} / \mathrm{ml} \\
+\operatorname{PVPP}(\%)\end{array}$ & $\begin{array}{l}\text { Error } \\
\text { estándar }\end{array}$ \\
\hline \multicolumn{6}{|c|}{ Extracto de hojas de edad variable (EV) } \\
\hline \multirow[t]{3}{*}{ Diciembre } & MOE & $5.14^{\mathrm{a}}$ & $8.60^{\mathrm{b}}$ & $12.97^{\mathrm{a}}$ & 4.40 \\
\hline & LFE & $1.60^{\mathrm{a}}$ & $66.69^{\mathrm{b}}$ & $86.33^{c}$ & 2.65 \\
\hline & $\mathrm{L}_{1}$ & $93.25^{\mathrm{a}}$ & $24.71^{\mathrm{b}}$ & $0.70^{\mathrm{c}}$ & 2.52 \\
\hline \multirow[t]{3}{*}{ Marzo } & MOE & $4.91^{\mathrm{a}}$ & $7.72^{\mathrm{a}}$ & $13.67^{\mathrm{a}}$ & 3.56 \\
\hline & LFE & $0.62^{\mathrm{a}}$ & $28.60^{\mathrm{b}}$ & $82.80^{c}$ & 0.79 \\
\hline & $\mathrm{L}_{1}$ & $94.46^{\mathrm{a}}$ & $63.69^{\mathrm{b}}$ & $3.54^{\mathrm{c}}$ & 3.97 \\
\hline \multirow[t]{3}{*}{ Junio } & MOE & $2.35^{\mathrm{a}}$ & $4.62^{\mathrm{a}}$ & $29.27^{\mathrm{a}}$ & 8.13 \\
\hline & LFE & $1.22^{\mathrm{a}}$ & $22.25^{\mathrm{a}}$ & $33.37^{\mathrm{b}}$ & 8.41 \\
\hline & $\mathrm{L}_{1}$ & $96.42^{\mathrm{a}}$ & $73.13^{\mathrm{a}}$ & $35.37^{\mathrm{b}}$ & 8.12 \\
\hline \multirow[t]{3}{*}{ Septiembre } & MOE & $7.37^{\mathrm{a}}$ & $9.86^{\mathrm{a}}$ & $10.16^{\mathrm{a}}$ & 1.11 \\
\hline & LFE & $0.14^{\mathrm{a}}$ & $25.11^{\mathrm{b}}$ & $26.58^{b}$ & 0.94 \\
\hline & $\mathrm{L}_{1}$ & $92.50^{\mathrm{a}}$ & $65.03^{\mathrm{b}}$ & $63.27^{b}$ & 1.69 \\
\hline \multicolumn{6}{|c|}{ Extractos de hojas de 90 días de edad (E90) } \\
\hline \multirow[t]{3}{*}{ Marzo } & MOE & $7.37^{\mathrm{a}}$ & $9.86^{\mathrm{b}}$ & $10.16^{\mathrm{c}}$ & 0.77 \\
\hline & LFE & $0.14^{\mathrm{a}}$ & $25.11^{\mathrm{b}}$ & $26.58^{\mathrm{c}}$ & 0.82 \\
\hline & $\mathrm{L}_{1}$ & $92.50^{\mathrm{a}}$ & $65.03^{\mathrm{b}}$ & $63.27^{\mathrm{b}}$ & 1.37 \\
\hline \multirow[t]{3}{*}{ Junio } & MOE & $0.37^{\mathrm{a}}$ & $3.48^{\mathrm{b}}$ & $41.09^{c}$ & 0.77 \\
\hline & LFE & $9.21^{\mathrm{a}}$ & $25.83^{\mathrm{b}}$ & $83.55^{\mathrm{c}}$ & 2.46 \\
\hline & $\mathrm{L}_{1}$ & $90.42^{\mathrm{a}}$ & $70.69^{b}$ & $2.36^{\mathrm{c}}$ & 3.11 \\
\hline \multirow[t]{3}{*}{ Septiembre } & MOE & $11.66^{\mathrm{a}}$ & $15.91^{\mathrm{a}}$ & $15.28^{\mathrm{a}}$ & 3.14 \\
\hline & LFE & $0.14^{\mathrm{a}}$ & $37.61^{\mathrm{b}}$ & $34.11^{\mathrm{b}}$ & 0.90 \\
\hline & $\mathrm{L}_{1}$ & $88.20^{\mathrm{a}}$ & $46.47^{\mathrm{b}}$ & $50.61^{b}$ & 1.90 \\
\hline \multirow[t]{3}{*}{ Diciembre } & MOE & $10.95^{\mathrm{a}}$ & $19.52^{\mathrm{b}}$ & $11.74^{\mathrm{a}}$ & 2.02 \\
\hline & LFE & $0.48^{\mathrm{a}}$ & $33.13^{\mathrm{b}}$ & $34.85^{\mathrm{b}}$ & 0.96 \\
\hline & $\mathrm{L}_{1}$ & $88.57^{\mathrm{a}}$ & $47.35^{\mathrm{b}}$ & $53.41^{\mathrm{c}}$ & 2.06 \\
\hline
\end{tabular}

${ }^{\text {abc }}$ Diferentes letras en la misma fila indican diferencia significativa entre los grupos PBS, extracto y extracto+PVPP $(P<0.05)$ 


\section{Prueba de inhibición del desenvaine larval (IDL)}

La $\mathrm{CE}_{50}$ obtenida con los diferentes extractos de G. floribundum de hojas EV y E90 con la prueba de IDL, se presenta en el Cuadro 4. Se observó un efecto significativo de la interacción entre edad de hojas y mes de cosecha. En el caso de los extractos de hojas EV, todos los meses de cosecha mostraron diferente actividad, siendo el extracto de junio el más activo y el de marzo el menos activo $(P<0.05)$. Por su parte, los extractos de hojas E90 también fueron diferentes para cada mes $(P<0.05)$, siendo el más activo el de septiembre y el menos activo el de junio.

Cuadro 4: Efecto de la edad de las hojas y del mes de cosecha sobre la concentración efectiva ( $\left.\mathrm{CE}_{50}\right)$ e intervalo de confianza de los extractos de hojas de Gymnopodium floribundum sobre el desenvaine de L3 de Haemonchus contortus

\begin{tabular}{|c|c|c|}
\hline & $\begin{array}{l}\text { CE50 } \\
(\mu \mathrm{g} / \mathrm{ml})\end{array}$ & $\begin{array}{l}\text { IC95\% } \\
(\mu \mathrm{g} / \mathrm{ml})\end{array}$ \\
\hline \multicolumn{3}{|c|}{ Extractos de hojas de edad variada $(\mathrm{EV})$} \\
\hline Diciembre & $199.9^{\mathrm{ef}}$ & $136.67-279.12$ \\
\hline Marzo & $283.5^{\mathrm{gh}}$ & $207.27-382.01$ \\
\hline Junio & $80.4^{\mathrm{a}}$ & $55.83-104.55$ \\
\hline Septiembre & $146.1^{\mathrm{bc}}$ & $119.93-175.37$ \\
\hline \multicolumn{3}{|c|}{ Extractos de hojas de 90 días de edad (E90) } \\
\hline Diciembre & $168.3^{\mathrm{de}}$ & $134.10-205.21$ \\
\hline Marzo & $146.1^{\mathrm{cd}}$ & $119.93-175.37$ \\
\hline Junio & $263.6^{\mathrm{fg}}$ & $245.33-281.28$ \\
\hline Septiembre & $108.4^{\mathrm{ab}}$ & $81.41-139.02$ \\
\hline
\end{tabular}

En el Cuadro 5 se presenta el efecto de los extractos de hojas de G. floribundum de diferente edad y mes de cosecha sobre los porcentajes de IDL de las $\mathrm{L}_{3}$ de $H$. contortus, con o sin la adición de PVPP para bloquear a los polifenoles. El uso de PVPP mostró que la inhibición del desenvaine se debe parcialmente a los polifenoles, y hace evidente que otros CS participan en la IDL. Además, los análisis de correlación no mostraron asociación entre los contenidos de FT, TT o TC, y la $\mathrm{CE}_{50}$ de IDL. 
Cuadro 5: Efecto de la incubación de $\mathrm{L}_{3}$ de Haemonchus contortus en diferentes extractos metanol:agua de Gymnopodium floribundum con y sin polivinilpolipirrolidona (PVPP) sobre el porcentaje de inhibición del desenvaine

\begin{tabular}{lclll}
\hline & $\begin{array}{l}\text { PBS } \\
(\boldsymbol{\%})\end{array}$ & $\begin{array}{l}\mathbf{1 , 2 0 0} \boldsymbol{\mu g} / \mathbf{m l} \\
(\boldsymbol{\%})\end{array}$ & $\begin{array}{l}\mathbf{1 , 2 0 0} \boldsymbol{\mu g} / \mathbf{m l}+\mathbf{P V P P} \\
(\boldsymbol{\%})\end{array}$ & $\begin{array}{l}\text { Error } \\
\text { estándar }\end{array}$ \\
\hline Extractos de hojas de edad variada (EV) & & & \\
Diciembre & $0.2^{\mathrm{a}}$ & $100.0^{\mathrm{b}}$ & $60.0^{\mathrm{c}}$ & 6.75 \\
Marzo & $0.0^{\mathrm{a}}$ & $100.0^{\mathrm{b}}$ & $65.5^{\mathrm{c}}$ & 9.94 \\
Junio & $3.4^{\mathrm{a}}$ & $100.0^{\mathrm{b}}$ & $45.7^{\mathrm{a}}$ & 20.80 \\
Septiembre & $2.9^{\mathrm{a}}$ & $100.0^{\mathrm{b}}$ & $79.3^{\mathrm{b}}$ & 13.25 \\
Extractos de hojas de 90 días de edad (E90) & & \\
Diciembre & $2.1^{\mathrm{a}}$ & $92.0^{\mathrm{b}}$ & $36.6^{\mathrm{a}}$ & 9.24 \\
Marzo & $3.1^{\mathrm{a}}$ & $100.0^{\mathrm{b}}$ & $53.5^{\mathrm{b}}$ & 11.18 \\
Junio & $0.3^{\mathrm{a}}$ & $100.0^{\mathrm{b}}$ & $76.1^{\mathrm{c}}$ & 3.34 \\
Septiembre & $0.4^{\mathrm{a}}$ & $100.0^{\mathrm{b}}$ & $86.7^{\mathrm{b}}$ & 2.51 \\
\hline \multicolumn{4}{r}{ abc Diferentes letras en la misma columna indican una diferencia significativa $(P<0.05)}$.
\end{tabular}

\section{Prueba de difusión radial para medir la precipitación de proteína (PP)}

La PP obtenida con los extractos de hojas de G. floribundum no mostró diferencias debidas a la edad de las hojas o el mes de cosecha (Cuadro 6). El análisis de correlación demostró que un mayor contenido de FT, TT o TC en los extractos no influyó sobre la PP.

Cuadro 6: Efecto de la edad y mes de cosecha de hojas de Gymnopodium floribundum sobre la precipitación de proteína (PP) medida por el método de difusión radial y su relación con el contenido de fenoles totales (FT), taninos totales (TT) y taninos condensados (TC)

\begin{tabular}{llll}
\hline & $\begin{array}{l}\text { PP-FT } \\
(\mathbf{m m} / \mathbf{m g})\end{array}$ & $\begin{array}{l}\text { PP-TT } \\
(\mathbf{m m} / \mathbf{m g})\end{array}$ & $\begin{array}{l}\text { PP-TC } \\
(\mathbf{m m} / \mathbf{m g})\end{array}$ \\
\hline Extractos de hojas de edad variada (EV) & & & \\
Diciembre & $9.29^{\mathrm{a}}$ & $64.65^{\mathrm{a}}$ & $2.75^{\mathrm{a}}$ \\
Marzo & $9.23^{\mathrm{a}}$ & $43.15^{\mathrm{a}}$ & $4.38^{\mathrm{a}}$ \\
Junio & $8.29^{\mathrm{a}}$ & $34.96^{\mathrm{a}}$ & $1.87^{\mathrm{a}}$ \\
Septiembre & $9.37^{\mathrm{a}}$ & $40.69^{\mathrm{a}}$ & $2.29^{\mathrm{a}}$ \\
Extractos de hojas de 90 días de edad (E90) & & \\
Diciembre & $10.05^{\mathrm{a}}$ & $42.65^{\mathrm{a}}$ & $2.09^{\mathrm{a}}$ \\
Marzo & $11.95^{\mathrm{a}}$ & $40.69^{\mathrm{a}}$ & $3.79^{\mathrm{a}}$ \\
Junio & $7.93^{\mathrm{a}}$ & $38.14^{\mathrm{a}}$ & $4.68^{\mathrm{a}}$ \\
Septiembre & $9.57^{\mathrm{a}}$ & $28.34^{\mathrm{a}}$ & $2.68^{\mathrm{a}}$ \\
Error estándar & 1.03 & 11.05 & 0.63 \\
\hline
\end{tabular}

${ }^{a}$ Valores en columnas con la misma literal no difieren significativamente $P>0.1$ 


\section{Discusión}

\section{Composición de polifenoles en los extractos de Gymnopodium floribundum}

Los valores reportados en el presente estudio para FT y TT son semejantes a los reportados previamente para extractos metanol:agua y acetona:agua elaborados con hojas de la misma especie de planta ${ }^{(11,12)}$. Un aspecto interesante del contenido de FT y TT es que se mantuvieron relativamente constantes para los diferentes extractos independientemente de la edad de las hojas o el mes de cosecha. En el caso de los FT, esto pudiera deberse a que la planta necesita una cantidad constante de estos compuestos ya que son intermediarios de diferentes rutas biosintéticas de la planta ${ }^{(30)}$. En el caso de los TT, que son compuestos más complejos, la semejanza en su contenido pudiera deberse a que estos son afectados por variables distintas a las dos evaluadas en el presente estudio.

En cuanto al contenido de TC, solo se tiene un estudio previo de un extracto de $G$. floribundum elaborado con hojas EV obtenido en época de $\operatorname{seca}^{(11)}$ y en éste se reportó un valor semejante al de hojas EV de marzo del presente estudio. Sin embargo, el presente estudio mostró que existen diferencias en el contenido de TC debidas a la interacción entre edad de hojas y mes de cosecha. La variación en el contenido de TC de hojas de $G$. floribundum debidas al mes de cosecha ya habían sido sugeridas previamente ${ }^{(1,13,31)}$. La diferencia en el contenido de TC fue solo evidente entre las hojas EV de marzo (mes de sequía) y junio (mes de lluvias), y de éstas últimas con respecto a las hojas E90 de junio. El mayor contenido de TC en las hojas EV de junio pudiera deberse a que las plantas usan los TC como una herramienta para defenderse de hongos y bacterias que proliferan en lluvias. Por otro lado, las hojas E90 no presentaron un mayor contenido de TC, en comparación con las hojas EV. Esto pudiera deberse a que los árboles de donde se cosecharon las hojas E90 fueron completamente defoliados 90 días antes. Por lo tanto, las hojas E90, que estaban en pleno crecimiento, tal vez no podían invertir más recursos de la planta en producir sustancias de defensa.

\section{Actividad antihelmíntica de extractos metanol:agua}

\section{Prueba de inhibición de la eclosión de huevos (EH)}

El extracto de hojas EV de diciembre inhibió significativamente la eclosión de huevos de $H$. contortus y esa inhibición se logró a una $\mathrm{CE}_{50}$ menor que la reportada previamente para el mismo tipo extracto de hojas $\mathrm{EV}^{(11)}$. Por otro lado, tres de los extractos de hojas E90 (junio, septiembre y diciembre) inhibieron la $\mathrm{EH}$, aunque estos extractos tuvieron una $\mathrm{CE}_{50}$ más alta que la reportada para hojas EV de este estudio y el reporte previo ${ }^{(11)}$. Con excepción del extracto de hojas EV de marzo, la nula o baja actividad sobre la EH por parte de los extractos 
metanol:agua de G. floribundum es similar a la reportada para otras plantas ricas en polifenoles y se ha sugerido que esta baja actividad contra huevos se debe a que los CS que se obtienen utilizando metanol o acetona como disolventes orgánicos ${ }^{(11,24,27)}$. El presente estudio confirmó también que la actividad contra huevos de $H$. contortus en los extractos metanol:agua de $G$. floribundum se manifiesta como la presencia de larvas atrapadas dentro de los huevos (LFE), tal como había sido reportado ${ }^{(2,24,27)}$. Así mismo, el uso de PVPP confirmó que los polifenoles no explican la actividad de inhibición de la EH, sino que el bloqueo de polifenoles incrementó el efecto de LFE en los meses de diciembre, marzo y junio para los extractos de hojas EV $(P<0.05)$, y en los meses de marzo y junio para los extractos de hojas E90 $(P<0.05)$.

\section{Prueba de inhibición del desenvaine larval (IDL) de Haemonchus contortus}

Todos los extractos de hojas de G. floribundum inhibieron el desenvaine de $\mathrm{L}_{3}$ de $H$. contortus. Estos resultados coinciden con los estudios previos usando extractos de $G$. floribundum, ya sea metanol:agua ${ }^{(11)}$ o acetona: agua $^{(12,13)}$. La mejor $\mathrm{CE}_{50}$ se observó para el extracto de hojas EV del mes de junio $(P<0.05)$, que a su vez fue el extracto con la mayor concentración de TC. Esta mayor actividad AH coincide con el momento en que $G$. floribundum empieza su mayor producción de hojas (época de lluvias) ${ }^{(15)}$. Como se mencionó, en la época de lluvias la planta pudiera usar los TC de sus hojas para defenderse del ataque de insectos, hongos y bacterias ${ }^{(4)}$. El alto contenido de TC en los meses de lluvia pudiera también limitar el ataque de herbívoros vertebrados como es el caso de los rumiantes, ya que estudios recientes demuestran que los pequeños rumiantes consumen menos follaje de G. floribundum en época de lluvias comparado con la época de seca ${ }^{(1,2)}$. Coincidentemente, es en la época de seca que las hojas de G. floribundum contienen menos $\mathrm{TC}^{(15)}$.

Los extractos de G. floribundum disminuyeron su actividad de IDL cuando los polifenoles fueron bloqueados con el PVPP $(P<0.05)$. Sin embargo, el PVPP solo bloqueó parcialmente la actividad de IDL de los extractos. Esto pudiera deberse a dos fenómenos: (a) no se usó suficiente PVPP para bloquear a todos los polifenoles en la solución, y (b) existen otros CS que son parcialmente responsables de la actividad IDL. Cualquiera de los dos fenómenos pudieran explicar la ausencia de correlación entre la actividad de IDL y los contenidos de FT, TT y TC. Esto sugiere que se deberían explorar dosis crecientes de PVPP cuando se realiza la prueba de IDL, para confirmar que la dosis usada sí bloquea a la mayoría o totalidad de los polifenoles. Por otro lado, sería necesario explorar qué otros CS pudieran ayudar a explicar la actividad de IDL no asociada a los polifenoles. Esto requeriría de un proceso de fraccionamiento biodirigido. Este tipo de proceso ha pemitido identificar la actividad de cromenona $^{(32)}$ y de derivados de ácidos fenólicos (cafeico, cumárico) sobre la inhibición de la eclosión de huevos de NGI de rumiantes ${ }^{(33,34)}$. 


\section{Ensayo de precipitación de proteína}

Se observó que todos los extractos precipitaron la proteína hemoglobina. Esto corrobora la actividad de PP que se ha reportado para otros árboles forrajeros ricos en polifenoles de Yucatán ${ }^{(14)}$. Sin embargo, estos autores determinaron que el extracto acetona:agua de $A$. pennatula tuvo fuerte asociación entre FT y la PP. En el caso de G. floribundum no se encontró correlación entre contenido de polifenoles y la PP. Lo anterior pudiera representar una oportunidad para que futuros trabajos de investigación pudieran ayudar a seleccionar individuos que den lugar a variedades de plantas con diferente contenido de polifenoles o con diferente actividad biológica de PP. Es necesario identificar qué factores adicionales influyen sobre la expresión de polifenoles en las hojas o su capacidad de PP. En este estudio se confirmó que los extractos de G. floribundum precipitan proteínas independientemente del mes de cosecha, edad de hojas o su contenido de polifenoles. Por lo tanto, los ovinos y caprinos pudieran aprovechar la actividad biológica (PP) de las hojas de G. floribundum como parte de una estrategia para sobrevivir en un ambiente donde predominan plantas ricas en proteínas (leguminosas). Esto es consistente con la hipótesis de que ovinos y caprinos pudieran consumir el follaje de G. floribundum para bloquear parte de la proteína de la dieta y ayudar a reducir la vía de eliminación de nitrógeno en la orina que es muy costosa para el $\operatorname{animal}^{(2,8)}$.

Dado que los extractos mostraron una buena PP medida con hemoglobina, se sugiere evaluar esta actividad de PP empleando otras proteínas que pudieran estar más cercanamente relacionadas con la actividad AH contra $H$. contortus. Por ejemplo, se podrían obtener proteínas directamente de las $\mathrm{L}_{3}$ (con o sin vaina) de $H$. contortus ya que estas fases de vida estarían en contacto con los polifenoles en el tracto gastrointestinal. Este contacto con los polifenoles se produce desde que entran en la boca del rumiante y se mantienen en contacto a lo largo del esófago, retículo-rumen, omaso y abomaso, hasta que realizan la invasión de la mucosa abomasal para establecerse y pasar a L4. También pudiera evaluarse la PP usando proteína de huevos de $H$. contortus, ya que estos están en contacto con los polifenoles a lo largo de todo el tránsito desde su salida del útero del gusano hembra, pasando por el abomaso, intestinos delgado y grueso hasta llegar a las heces. Estas evaluaciones pudieran servir como modelo para estudiar la interacción parásito-hospedero-planta.

\section{Conclusiones e implicaciones}

Existen diferencias en la composición de TC asociadas a la interacción entre la edad de las hojas y el mes de cosecha en los extractos metanol:agua de hojas de G. floribundum. La actividad de inhibición de la eclosión de huevos fue evidente solo en el extracto de hojas EV de diciembre, y tres extractos de hojas E90 presentaron actividad a altas concentraciones. Todos los extractos mostraron actividad de inhibición del desenvaine de larvas $\mathrm{L}_{3}$, siendo el 
extracto de hojas EV de junio el que tuvo mejor actividad. Los polifenoles de los extractos mostraron actividad de PP y se asociaron a la inhibición del desenvaine larval de $H$. contortus. Sin embargo, no explican la actividad contra huevos de H. contortus. La principal implicación del presente trabajo fue demostrar por primera vez que los FT y TT de extractos de hojas de G. floribundum no son modificados significativamente por la edad de las hojas y mes de cosecha, en tanto que los TC sí varían. Además, se demostró que la actividad biológica de los polifenoles es fuerte para la PP, es parcial para la IDL y es independiente de la EH. Esta información sirve como base para la toma de decisiones con respecto a la aplicación de las hojas de G. floribundum en la nutrición de rumiantes y para la evaluación del potencial nutraceútico contra $H$. contortus. La variabilidad encontrada también indica que existe potencial para la selección de individuos de esta especie que se orienten hacia un mayor o menor contenido o actividad de TC.

\section{Agradecimientos}

Al CONACYT-México por el financiamiento de este trabajo (Proyecto-CB-2013-01221608). G.I. Ortíz-Ocampo reconoce al Consejo Nacional de Ciencia y Tecnología de México (CONACYT) por la beca otorgada para su estudio de doctorado (referencia 257653). Mancilla-Montelongo agradece el financiamiento del "Programa de Investigadores e Investigadoras por México" CONACYT (Proyecto No. 692). Agradecemos a todo el equipo del Campus su valiosa contribución durante el trabajo de campo: P.G. González-Pech, J. Ventura-Cordero, F.A. Méndez-Ortiz, E. Ramos-Bruno y F. Torres-Salazar. También agradecemos a los tutores: V. Parra-Tabla, J.J. Ortíz-Díaz, L.R. Borges-Argáez. Agradecemos también el apoyo de I.C. Trinidad-Martínez en el laboratorio de Diagnóstico de la FMVZ-UADY.

\section{onflicto de intereses}

Los autores declaramos no tener conflicto de interés con la publicación del presente estudio.

\section{Literatura citada:}

1. González-Pech PG, Torres-Acosta JFJ, Sandoval-Castro CA, Tun-Garrido J. Feeding behavior of sheep and goats in a deciduous tropical forest during the dry season: the same menu consumed differently. Small Ruminant Res 2015;(133):128-134.

2. Ventura-Cordero J, González-Pech PG, Torres-Acosta JFJ, Sandoval-Castro CA, TunGarrido J. Sheep and goat browsing a tropical deciduous forest during the rainy season: why does similar plant species consumption result in different nutrient intake? Anim Prod Sci 2019;59(1):66-72. 
3. Cuevas-Glory L, Sosa-Moguel O, Ortiz-Vázquez E, Sauri-Duch E, Pino A. Volatile constituents of tzizilché flower (Gymnopodium floribundum Rolfe) from Yucatán Peninsula, Mexico. J Esse Oil Res 2012;(24):359-361.

4. Ek de Val. Herbivoría. En: Ecología y evolución de las interacciones bióticas. En: Ek de val, Boege K, editors. Ecología y evolución de las interacciones bióticas. $1^{\text {a }}$ ed. México, DF: FCE, Fondo de Cultura Económica 2012:43-75.

5. Graça MAS, Bärlocher F. Radial diffusion assay for tannins. In: Bärlocher F, et al. editors. Methods to study litter decomposition. Germany Springer 2020;163-167.

6. Zimmer M, Topp W. Species-specific utilization of food sources by sympatric woodlice (Isopoda: Oniscidea). J Anim Ecol 2008;68(6):1071-1082.

7. Min BR, Barry TN, Atwood GT, McNabb WC. The effect of condensed tannins on the nutrition and health of ruminants fed fresh temperate forages: a review. Anim Feed Sci Tech 2003;106(1-4):3-19.

8. Torres-Fajardo RA, Navarro-Alberto JA, Ventura-Cordero J, González-Pech PG, Sandoval-Castro CA, Chan-Pérez JI, et al. Intake and selection of goats grazing heterogeneous vegetation: effect of gastrointestinal nematodes and condensed tannins. Rangel Ecol Manag 2019;72(6):946-953.

9. Bennick A. Interactions of plant polyphenols with salivary proteins. Crit Rev Oral Biol Med 2002;13(2):184-196.

10. Makkar HPS, Francis G, Becker K. Bioactivity of phytochemicals in some lesser-known plants and their effects and potential applications in livestock and aquaculture production systems. Anim 2007;1(9);1371-1391.

11. Castañeda-Ramírez GS, Torres-Acosta JFJ, Sandoval-Castro CA, González-Pech PG, Parra-Tabla VP, Mathieu C. Is there a negative association between the content of condensed tannins, total phenols, and total tannins of tropical plant extracts and in vitro anthelmintic activity against Haemonchus contortus eggs? Parasitol Res 2017;116(12): 3341-3348.

12. Castañeda-Ramírez GS, Rodríguez-Labastida M, Ortíz-Ocampo GI, González-Pech PG, Ventura-Cordero J, Borges-Argáez R, et al. An in vitro approach to evaluate the nutraceutical value of plant foliage against Haemonchus contortus. Parasitol Res 2018;117(12):3979-3991. 
13. Méndez-Ortiz FA, Sandoval-Castro CA, Ventura-Cordero J, Sarmiento-Franco LA, Santos-Ricalde RH, Torres-Acosta JFJ. Gymnopodium floribundum fodder as a model for the in vivo evaluation of nutraceutical value against Haemonchus contortus. Trop Anim Health Prod 2019;51(6):1501-1599.

14. Alonso-Díaz MA, Torres-Acosta JFJ, Sandoval-Castro CA, Capetillo-Leal CM. Polyphenolic compounds of nutraceutical trees and the variability of their biological activity measured by two methods. Trop Subtrop Agroecosyst 2010;12(3):649-656.

15. Ortiz-Ocampo GI, Sandoval-Castro CA, González-Pech PG, Mancilla-Montelongo G, Ventura-Cordero J, Castañeda-Ramírez GS, et al. Month of harvest and age of leaves are key modifiers of the bromatological composition and polyphenol content of Gymnopodium floribundum leaves. Flora [sometido] 2021.

16. Hoste H, Torres-Acosta JFJ, Alonso-Díaz MA, Brunet S, Sandoval-Castro C, Houzangbe-Adote S. Identification and validation of bioactive plants for the control of gastrointestinal nematodes in small ruminants. Trop Biomed 2008;25(1):56-72.

17. Verma N, Shukla S. Impact of various factors responsible for fluctuation in plant secondary metabolites. J Appl Res Med and Arom Plants 2015;2(4):105-113.

18. García E. Modificaciones al Sistema de clasificación climática de Köppen. Quinta ed. Instituto de Geografía, Universidad Nacional Autónoma de México (UNAM). México. 2004:90.

19. Makkar HPS. Quantification of tannins in tree and shrub foliage. A laboratory manual. Food and Agriculture Organization of the United Nations/International Atomic Energy Agency (FAO/IAEA), Vienna, Austria 2003:49-53.

20. Price ML, Van-Scoyoc S, Butler LG. A critical evaluation of the vanillin reaction assay for tannin in sorghum grain. J Agric Food Chem 1978;26(5):1214-1218.

21. Castañeda-Ramírez GS, Matheieu C, Vilarem G, Hoste H, Mendoza-de-Gives P, González-Pech PG, et al. Age of Haemonchus contortus third stage infective larvae is a factor influencing the in vitro assessment of anthelmintic properties of tannin containing plant extracts. Vet Parasitol 2017;243(30):130-134.

22. Von Samson-Himmelstjerna G, Coles GC, Jackson F, Bauer C, Borgsteede F, Cirak VY, et al. Standardization of the egg hatch test for the detection of benzimidazole resistance in parasitic nematodes. Parasitol Res 2009;105(3):825-834. 
23. Jackson $\mathrm{F}$, Hoste $\mathrm{H}$. In vitro methods for the primary screening of plant products for direct activity against ruminant gastrointestinal nematodes. In: Vercoe PE, et al. editors. In vitro screening of plant resources for extra-nutritional attributes in ruminants: Nuclear and related methodologies. UK: Springer; 2010:25-45.

24. Vargas-Magaña JJ, Torres-Acosta JFJ, Aguilar-Caballero AJ, Sandoval-Castro CA, Hoste H, Chan-Pérez JI. Anthelmintic activity of acetone-water extracts against Haemonchus contortus eggs: interactions between tannins and other plant secondary compounds. Vet Parasitol 2014;206(3-4):322-327.

25. Hagerman AE. Radial diffusion method for determination tannin in plant extracts. $\mathbf{J}$ Chem Ecol 1987;13(3):437-449.

26. Minitab 16 Statistical software 2013. Computer software Minitab ver.16.2.4. State College, PA: Minitab Inc. (www.minitab.com). Accessed: Nov 3, 2020.

27. Chan-Pérez JI, Torres-Acosta JFJ, Sandoval-Castro AC, Hoste H, Castañeda-Ramírez GS, Vilarem G, et al. In vitro susceptibility of ten Haemonchus contortus isolates from different geographical origins towards acetone:water extracts of two tannin rich plants. Vet Parasitol 2016;(217):53-60.

28. Chan-Pérez JI, Torres-Acosta JFJ, Sandoval-Castro AC, Castañeda-Ramírez GS, Vilarem G, Mathieu C, et al. Susceptibility of ten Haemonchus contortus isolates from different geographical origins towards acetone:water extracts of polyphenol-rich plants. Part 2: Infective L 3 larvae. Vet Parasitol 2017;(240):11-16.

29. LeOra Software. Polo Plus. Probit and logit analysis. Berkeley, California, U.S.A., LeOra Software. 2004.

30. Winkel-Shirley B. Flavonoid biosynthesis. A colorful model for genetics, biochemistry, cell biology, and biotechnology. Plant Physiol 2001;126(2):485-493.

31. Ventura-Cordero J, González-Pech PG, Jaimez-Rodríguez PR, Ortiz-Ocampo GI, Sandoval-Castro CA, Torres-Acosta JFJ. Gastrointestinal nematode infection does not affect selection of tropical foliage by goats in cafeteria trial. Trop Anim Health Prod 2017;49(1):97-104.

32. Von Son-de Fernex E, Alonso-Díaz MÁ, Valles-de la Mora B, Mendoza-de Gives P, González-Cortazar M, Zamilpa A. Anthelmintic effect of 2H-chromen-2-one isolated from Gliricidia sepium against Cooperia punctata. Exp Parasitol 2017;(178):1-6. 
33. Castillo-Mitre GF, Olmedo-Juárez A, Rojo-Rubio R, González-Cortázar M, Mendozade Gives P, Hernández-Beteta EE, et al. Caffeoyl and coumaroyl derivatives from Acacia cochliacantha exhibit ovicidal activity against Haemonchus contortus. J Ethnopharmacol 2017;(204):125-131.

34. Castañeda-Ramírez GS, Torres-Acosta JFJ, Sandoval-Castro CA, Borges-Argáez R, Cáceres-Farfán M, Mancilla-Montelongo G, et al. Bio-guided fractionation to identify Senegalia gaumeri leaf extract compounds with anthelmintic activity against Haemonchus contortus eggs and larvae. Vet Parasitol 2019;(270):13-19. 